\title{
Network analysis of genes involved in the enhancement of hyperthermia sensitivity by the knockdown of BAG3 in human oral squamous cell carcinoma cells
}

\author{
TATSUYA YUNOKI $^{1}$, YOSHIAKI TABUCHI ${ }^{2}$, ATSUSHI HAYASHI $^{1}$ and TAKASHI KONDO ${ }^{3}$ \\ ${ }^{1}$ Department of Ophthalmology, Graduate School of Medicine and Pharmaceutical Sciences, University of Toyama; \\ ${ }^{2}$ Division of Molecular Genetics Research, Life Science Research Center, University of Toyama; \\ ${ }^{3}$ Department of Radiological Sciences, Graduate School of Medicine and Pharmaceutical Sciences, \\ University of Toyama, Toyama 930-0194, Japan
}

Received November 25, 2015; Accepted May 16, 2016

DOI: $10.3892 / \mathrm{ijmm} .2016 .2621$

\begin{abstract}
BCL2-associated athanogene 3 (BAG3), a co-chaperone of the heat shock $70 \mathrm{kDa}$ protein (HSPA) family of proteins, is a cytoprotective protein that acts against various stresses, including heat stress. The aim of the present study was to identify gene networks involved in the enhancement of hyperthermia (HT) sensitivity by the knockdown (KD) of BAG3 in human oral squamous cell carcinoma (OSCC) cells. Although a marked elevation in the protein expression of BAG3 was detected in human the OSCC HSC-3 cells exposed to $\mathrm{HT}$ at $44^{\circ} \mathrm{C}$ for $90 \mathrm{~min}$, its expression was almost completely suppressed in the cells transfected with small interfering RNA
\end{abstract}

Correspondence to: Professor Yoshiaki Tabuchi, Division of Molecular Genetics Research, Life Science Research Center, University of Toyama, 2630 Sugitani, Toyama 930-0194, Japan

E-mail: ytabu@cts.u-toyama.ac.jp

Abbreviations: AIM2, absent in melanoma 2; ATF2, activating transcription factor 2; BAG, BCL2-associated athanogene; BNIP3, BCL2/adenovirus E1B $19 \mathrm{kDa}$ interacting protein 3; bZIP, basicregion leucine zipper; CEBPB, CCAAT/enhancer binding protein $\beta$; CLU, clusterin; DDIT3, DNA damage inducible transcript 3; DDX58, DEAD box polypeptide 58; DNAJ, DnaJ (Hsp40) homolog; FBS, fetal bovine serum; GAPDH, glyceraldehyde 3-phosphate dehydrogenase; GCH1, GTP cyclohydrolase 1; GSK3B, glycogen synthase kinase $3 \beta$; HSPA, heat shock $70 \mathrm{kDa}$ protein; HSPB, heat shock $27 \mathrm{kDa}$ protein; HSPD, heat shock $60 \mathrm{kDa}$ protein; HSPH, heat shock $105 \mathrm{kDa} / 110 \mathrm{kDa}$ protein; HSPs, heat shock proteins; HT, hyperthermia; ISG15, ISG15 ubiquitin-like modifier; KD, knockdown; MAP1LC3B, microtubule-associated protein 1 light chain 3 beta; MAPK12, mitogen-activated protein kinase 12; OSCC, oral squamous cell carcinoma; qPCR, quantitative polymerase chain reaction; RPS6KA2, ribosomal protein S6 kinase, $90 \mathrm{kDa}$, polypeptide 2; SDS-PAGE, sodium dodecyl sulfate-polyacrylamide gel electrophoresis; siRNA, small interfering RNA; SMAD2, SMAD family member 2; SQSTM1, sequestosome 1

Key words: hyperthermia, BCL2-associated athanogene 3 knockdown, microarray, gene network, human oral squamous cell carcinoma cell against BAG3 (siBAG) under normal and HT conditions. The silencing of BAG3 also enhanced the cell death that was increased in the HSC-3 cells by exposure to HT. Global gene expression analysis revealed many genes that were differentially expressed by $>2$-fold in the cells exposed to HT and transfected with siBAG. Moreover, Ingenuity ${ }^{\circledR}$ pathways analysis demonstrated two unique gene networks, designated as Pro-cell death and Anti-cell death, which were obtained from upregulated genes and were mainly associated with the biological functions of induction and the prevention of cell death, respectively. Of note, the expression levels of genes in the Pro-cell death and Anti-cell death gene networks were significantly elevated and reduced in the $\mathrm{HT}+\mathrm{BAG} 3-\mathrm{KD}$ group compared to those in the HT control group, respectively. These results provide further insight into the molecular mechanisms involved in the enhancement of HT sensitivity by the silencing of BAG3 in human OSCC cells.

\section{Introduction}

Hyperthermia (HT) therapy in combination with either chemotherapy, radiotherapy or both are used for patients with cancer in various organs. The anticancer effects of these combination therapies have been verified in many clinical trials (1-4). However, the acquisition of thermotolerance in cancer cells, which is at least partly due to an increase in the levels of heat shock proteins (HSPs), attenuates the therapeutic effects of HT $(5,6)$. HSPs function as molecular chaperones, and their epxression is induced by various stresses, particularly heat. Moreover, it has been recognized that these proteins exert potent cytoprotective effects, which prevent cell death $(7,8)$. HSPs consist of several family members, including DnaJ (Hsp40 homolog (DNAJ), heat shock $70 \mathrm{kDa}$ protein (HSPA), heat shock $27 \mathrm{kDa}$ protein (HSPB), heat shock $60 \mathrm{kDa}$ protein (HSPD) and heat shock $105 \mathrm{kDa} / 110 \mathrm{kDa}$ protein (HSPH), and among these, HSPA1A plays a major role as a molecular chaperone $(9,10)$.

BCL2-associated athanogene (BAG) family proteins, an ubiquitous family of chaperone regulators, have been found to be associated with the anti-apoptotic protein, BCL2, and also to interact with HSPA proteins, such as HSPA1A and 
HSPA8 $(11,12)$. Among the BAG proteins, the expression of BAG3 has been reported to be regulated, at least in part, by the activation of heat shock transcription factor 1 as in the cases of HSPs $(13,14)$. Under normal conditions, the expression level of BAG3 is relatively low, whereas a significant elevation in its protein level is observed in cells exposed to stressors, such as heavy metals (15), heat (16-18), oxidative stress (19) and ultrasound (20). It has also been indicated that BAG3 is abundantly expressed in a variety of cancers, and is involved in cellular processes such as cell growth and cell death (11,12,16,21-24). Liu et al (25) previously reported that silencing the BAG3 gene sensitizes leukemic cells to compound-induced cell injury. Recently, we clearly demonstrated that the inhibition of BAG3 improves cell death sensitivity to HT in cancer cells $(17,18)$. However, the detailed molecular mechanisms underling the enhancement of HT sensitivity by BAG3 knockdown (KD) in cancer cells have not yet been elucidated.

In the present study, we examined gene expression patterns in human oral squamous cell carcinoma (OSCC) HSC-3 cells exposed to HT and transfected with small interfering RNA (siRNA) against BAG3 using a global-scale microarray system. In addition, gene network analysis of differentially expressed genes was performed using computational gene expression analysis tools.

\section{Materials and methods}

Cell culture and exposure to HT. Human OSCC HSC-3 cells were obtained from the Human Science Research Resources Bank, Japan Health Sciences Foundation (Tokyo, Japan). The HSC-3 cells were cultured in E-MEM (Wako Pure Chemical Industries, Ltd., Osaka, Japan) supplemented with $10 \%$ fetal bovine serum (FBS) at $37^{\circ} \mathrm{C}$ in humidified air with $5 \% \mathrm{CO}_{2}$ and 95\% air. Exposure to HT was were performed by immersing plastic culture vessels containing the attached cells in a water bath at $44^{\circ} \mathrm{C}$ for $90 \mathrm{~min}$. Following exposure to HT, the cells were incubated for $6-24 \mathrm{~h}$ at $37^{\circ} \mathrm{C}$, as previously described (26).

siRNA transfection. A siRNA (siBAG; GGUGGAUUCUAAA CCUGUU) targeting BAG3 for BAG3-KD was designed by Nippon EGT Co., Ltd. (Toyama, Japan). Luciferase siRNA (siLuc; CGUACGCGGAAUACUUCGA) was used as a negative control siRNA. The cells were incubated in Opti-MEM ${ }^{\circledR} \mathrm{I}$ Reduced Serum Medium containing $20 \mathrm{nM}$ siRNA and Lipofectamine $^{\text {TM }}$ RNAiMAX (both from Life Technologies Japan, Ltd., Tokyo, Japan) at $37^{\circ} \mathrm{C}$. Six hours following transfection, the medium was exchanged for E-MEM supplemented with $10 \% \mathrm{FBS}$, and the cells were then maintained at $37^{\circ} \mathrm{C}$ for $42 \mathrm{~h}$, as previously described (18).

Measurements of cell growth and cell death. The number of cells was counted using a hematocytometer. When the cell death was evaluated, the cells were treated with $0.2 \%$ trypan blue solution (NanoEnTek Inc., Seoul, Korea) at room temperature for $5 \mathrm{~min}$. The number of dead cells (stained) and viable cells (unstained) was counted using an $\mathrm{EVE}^{\mathrm{TM}}$ automatic cell counter (NanoEnTek Inc.).

Sodium dodecyl sulfate-polyacrylamide gel electrophoresis (SDS-PAGE) and western blot analysis. The cells were dissolved in lysis buffer $(150 \mathrm{mM} \mathrm{NaCl}, 1 \%$ Nonidet P-40 and $50 \mathrm{mM}$ Tris- $\mathrm{HCl}, \mathrm{pH}$ 8.0) containing a protease inhibitor cocktail (Nacalai Tesque Inc., Kyoto, Japan). SDS-PAGE and western blot analysis were carried out as previously described $(27,28)$. The primary antibodies used were as follows: a rabbit monoclonal anti-BAG3 antibody (GTX62327; GeneTex Inc., Irvine, CA, USA) and a mouse monoclonal anti-glyceraldehyde 3-phosphate dehydrogenase (GAPDH) antibody (MAB374; Millipore Co., Temecula, CA, USA). Immunoreactive proteins were visualized using a luminescent image analyzer (LAS-4000 mini; GE Healthcare, Tokyo, Japan) using an enhanced chemiluminescence detection system. GAPDH served as a loading control.

RNA isolation. Total RNA was extracted from cells using a NucleoSpin ${ }^{\circledR}$ RNA isolation kit (Macherey-Nagel GmbH \& Co., Düren, Germany) along with on-column DNase I treatment. The RNA quality was analyzed using a Bioanalyzer 2100 (Agilent Technologies, Inc., Santa Clara, CA, USA). RNA samples with RNA integrity number (RIN) values $>9.5$ were considered acceptable.

Quantitative (real-time) polymerase chain reaction ( $q P C R)$. qPCR was performed on a Real-Time PCR system Mx3005P (Agilent Technologies, Inc.) using SYBR ${ }^{\circledR}$ Premix Ex Taq ${ }^{\mathrm{TM}}$ II (Takara Bio, Inc., Shiga, Japan) according to the manufacturer's instructions. Reverse transcriptase reaction was carried out with total RNA using a random 6 mers and an oligo dT primer (PrimeScript RT reagent kit; Takara Bio, Inc.). The reaction was carried out using the specific primers: human BAG3 forward and reverse, CGACCAGGCTACATTCCCAT and TCTGGCT GAGTGGTTTCTGG, respectively; human GAPDH forward and reverse, AAGGCTGGGGCTCATTTGCA and ATGACC TTGCCCACAGCCTT, respectively. The temperature cycling conditions for each primer consisted of $10 \mathrm{~min}$ at $95^{\circ} \mathrm{C}$ followed by 40 cycles for $10 \mathrm{sec}$ at $95^{\circ} \mathrm{C}$ and $40 \mathrm{sec}$ at $60^{\circ} \mathrm{C}$. The mRNA expression level of BAG3 was normalized with respect to the mRNA expression level of GAPDH, as described in a previous study of ours (18).

Microarray gene expression analysis. Microarray gene expression analysis was performed using a GeneChip ${ }^{\circledR}$ system with a Human Genome U133-plus 2.0 array, which was spotted with 54,675 probe sets (Affymetrix, Inc., Santa Clara, CA, USA) according to the manufacturer's instructions. In brief, $500 \mathrm{ng}$ of total RNA was used to synthesize cRNA with a GeneChip ${ }^{\circledR}$ 3' IVT Express kit (Affymetrix, Inc.). Fragmentated biotin-labeled cRNA was hybridized to the array at $45^{\circ} \mathrm{C}$ for $16 \mathrm{~h}$. After the staining with streptavidin-phycoerythrin, the array was scanned using a probe array scanner. The obtained hybridization intensity data were analyzed using GeneSpring ${ }^{\circledR}$ GX software (Agilent Technologies, Inc.) to extract the significant genes. To examine gene ontology, including biological processes, cellular components, molecular functions and gene networks, the obtained data were analyzed using Ingenuity ${ }^{\circledR}$ pathway analysis tools (Ingenuity Systems, Inc., Mountain View, CA, USA), as previously described $(29,30)$.

Statistical analysis. Data are shown as the means \pm SD. The Student's t-test was used for statistical analysis and 


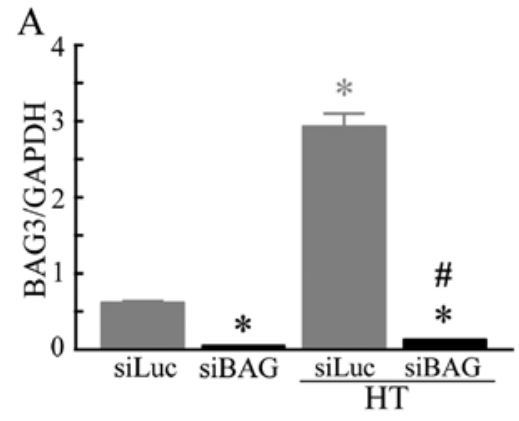

B

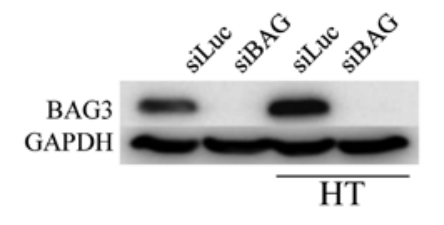

Figure 1. Effects of BCL2-associated athanogene 3 (BAG3)-knockdown (KD) on the mRNA and protein expression levels of BAG3 in HSC-3 cells exposed to hyperthermia (HT). HSC-3 cells transfected with luciferase siRNA (siLuc) or BAG3 siRNA (siBAG) were incubated at $37^{\circ} \mathrm{C}$ or $44^{\circ} \mathrm{C}$ for 90 min $(\mathrm{HT}$ exposure). Six hours later, the cells were harvested. (A) qPCR was performed with specific primers for BAG3 or glyceraldehyde 3-phosphate dehydrogenase (GAPDH). The mRNA level of BAG3 was normalized to the expression level of GAPDH. Data are presented as the means $\pm \mathrm{SD}(\mathrm{n}=4)$; ${ }^{*} \mathrm{P}<0.05$ vs. the control (siLuc transfection only); ${ }^{\text {P }}<0.05$ vs. the HT-exposed group. (B) Western blot analysis was performed using specific primary antibodies for BAG3 and GAPDH. GAPDH served as a loading control.
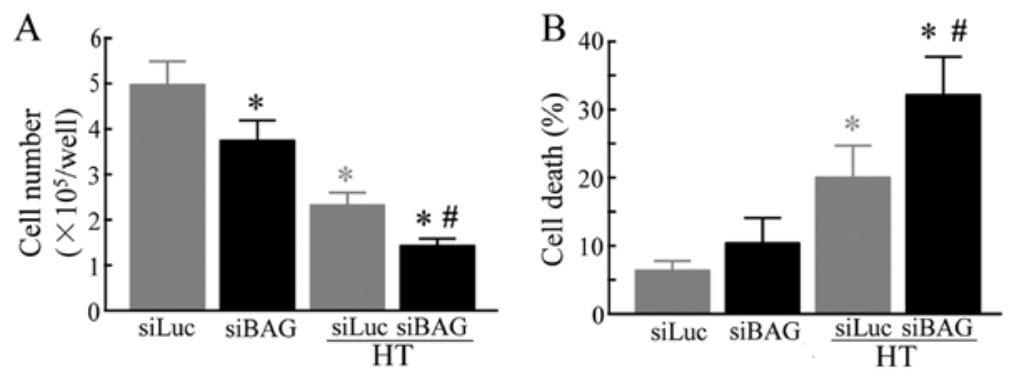

Figure 2. Effects of BCL2-associated athanogene 3 (BAG3)-knockdown (KD) on the growth and cell of HSC-3 cells exposed to hyperthermia (HT). HSC-3 cells transfected with luciferase siRNA (siLuc) or BAG3 siRNA (siBAG) were incubated at $37^{\circ} \mathrm{C}$ or $44^{\circ} \mathrm{C}$ for 90 min (HT exposure). (A) The cell number and (B) cell death were evaluated $24 \mathrm{~h}$ after HT exposure. Data are presented as the means $\pm \mathrm{SD}(\mathrm{n}=4)$; ${ }^{*} \mathrm{P}<0.05$ vs. the control (siLuc transfection only); ${ }^{\text {} P}<0.05$ vs. the HT-exposed group.

P-values $<0.05$ were considered to indicate statistically significant differences.

\section{Results}

Effects of BAG3-KD on the growth and death of HSC-3 cells exposed to HT. Although the mRNA expression level of BAG3 was relatively low in the HSC-3 cells transfected with siLuc (control), in the cells subjected to both siLuc transfection and HT exposure at $44^{\circ} \mathrm{C}$ (HT control), a significantly increased expression level of BAG3 was observed. A significant decrease in the mRNA expression level of BAG3 was detected in the cells transfected with siBAG under both the control (siLuc) and HT conditions (Fig. 1A). The results of western blot analysis clearly demonstrated that the protein expression level of BAG3 was significantly increased in the cells exposed to HT. Transfection of the cells with siBAG almost completely inhibited the protein expression level of BAG3 under either condition (Fig. 1B). We then evaluated whether BAG3-KD affected the growth and death of HSC-3 cells exposed to HT. At the normal temperature, transfection of the cells with siBAG significantly suppressed the cell number compared to the control group. HT markedly decreased cell growth, and a further decrease in the number of cells was observed in the cells subjected to both siBAG transfection and exposure to HT to those exposed to HT alone (Fig. 2A). HT significantly enhanced cell death. Moreover, a significant increase in cell death was observed in the cells subjected to both siBAG transfection and exposure to HT compared to those exposed to HT alone. These results indicate that the silencing of BAG3 enhances the sensitivity of human OSCC HSC-3 cells to HT (Fig. 2B).

Global gene expression analysis. To identify genes involved in the enhancement of HT sensitivity by BAG3-KD, global-scale gene expression analysis was carried out using a GeneChip ${ }^{\circledR}$ system with a Human Genome U133-plus 2.0 array, which was spotted with 54,675 probe sets. Complete lists of probe sets from all samples are available on the Gene Expression Omnibus, a public database (accession number, GSE75127). GeneSpring software was used to analyze gene expression in the HSC-3 cells subjected to both HT exposure and siLuc (HT control) or siBAG transfection (HT + BAG3-KD), and revealed that many genes were differentially regulated by a factor of $\geq 2.0$. The Venn diagram in Fig. 3 summarizes the numbers of specifically and commonly expressed genes in each group. The total numbers of genes that were found to be differentially expressed were 913 (331 up- and 582 downregulated genes) and 1,892 (679 up- and 1,213 downregulated genes) in the HT control and HT + BAG3-KD groups, respectively. The numbers of commonly up- and downregulated genes were 204 and 303, respectively (Fig. 3A and B).

Identification of biological functions and gene networks. In order to identify the biological functions and gene networks in differentially expressed genes involved in the enhancement of HT sensitivity by BAG3-KD, functional category and gene 
Table I. Top three biological functions in differentially expressed genes.

\begin{tabular}{|c|c|c|}
\hline Name & P-value & Number of molecules \\
\hline \multicolumn{3}{|l|}{ Upregulated } \\
\hline \multicolumn{3}{|l|}{ HT control only $(75)^{\mathrm{a}}$} \\
\hline Cell growth and proliferation & $5.02 \mathrm{E}-05-4.19 \mathrm{E}-02$ & 36 \\
\hline Post-translational modification & $1.20 \mathrm{E}-04-3.51 \mathrm{E}-02$ & 6 \\
\hline Protein folding & $1.20 \mathrm{E}-04-2.12 \mathrm{E}-02$ & 4 \\
\hline \multicolumn{3}{|l|}{ HT + BAG3-KD only $(263)^{\mathrm{a}}$} \\
\hline Cell growth and proliferation & $1.47 \mathrm{E}-05-2.73 \mathrm{E}-02$ & 123 \\
\hline Cell death and survival & 3.35E-05-2.73E-02 & 121 \\
\hline Cellular development & 1.93E-04-2.73E-02 & 92 \\
\hline \multicolumn{3}{|l|}{ Commonly regulated $(133)^{\mathrm{a}}$} \\
\hline Cell death and survival & 2.03E-17-2.70E-03 & 82 \\
\hline Cell growth and proliferation & 4.39E-14-2.70E-03 & 84 \\
\hline Cell cycle & $1.26 \mathrm{E}-12-2.70 \mathrm{E}-03$ & 39 \\
\hline \multicolumn{3}{|l|}{ Downregulated } \\
\hline \multicolumn{3}{|l|}{ HT control only $(62)^{\mathrm{a}}$} \\
\hline Cell cycle & 7.27E-04-4.99E-02 & 17 \\
\hline Gene expression & 3.52E-03-4.63E-02 & 6 \\
\hline Protein synthesis & 4.88E-04-1.57E-02 & 3 \\
\hline \multicolumn{3}{|l|}{ HT + BAG3-KD only (432) ${ }^{\mathrm{a}}$} \\
\hline Cellular development & 2.20E-06-2.64E-02 & 123 \\
\hline Cell growth and proliferation & 2.20E-06-2.70E-02 & 121 \\
\hline Cell death and survival & 1.28E-05-2.70E-02 & 92 \\
\hline \multicolumn{3}{|l|}{ Commonly regulated $(108)^{\mathrm{a}}$} \\
\hline RNA post-transcriptional modification & 4.19E-05-3.58E-02 & 9 \\
\hline Cell cycle & 2.90E-04-4.74E-02 & 32 \\
\hline Cell morphology & 2.90E-04-3.58E-02 & 26 \\
\hline
\end{tabular}

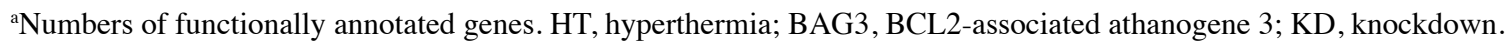

A Upregulated

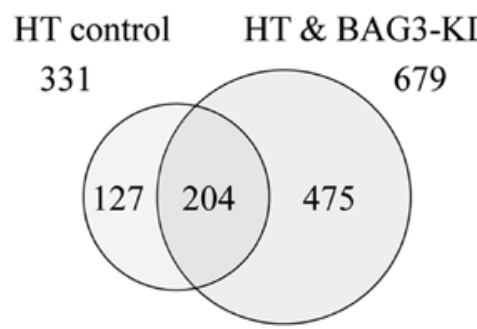

B Downregulated

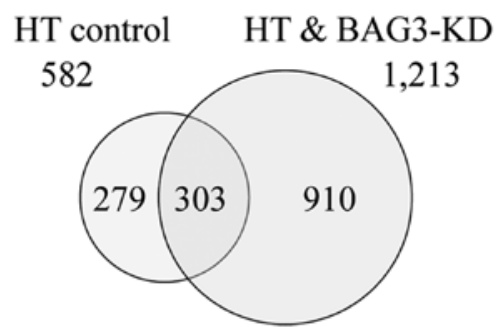

Figure 3. Venn diagram of genes that were differentially expressed in BCL2-associated athanogene 3 (BAG3)-knockdown (KD) HSC-3 cells under hyperthermia (HT) exposure conditions. HSC-3 cells transfected with luciferase siRNA (siLuc) or BAG3 siRNA (siBAG) were incubated at $37^{\circ} \mathrm{C}$ or $44^{\circ} \mathrm{C}$ for $90 \mathrm{~min}$ (HT exposure). Six hours following exposure to HT, total RNA was extracted. Gene expression analysis was carried out using a GeneChip microarray system and GeneSpring software. (A) The numbers of upregulated and (B) downregulated genes are shown. HT control indicates cells subjected to both HT exposure and transfection with siLuc; HT + BAG3-KD indicates both exposure to HT and transfection with siBAG.

network analyses were conducted by use of the Ingenuity Pathways Knowledge Base. We identified many functionally annotated genes, and the top 3 biological functions in each group are summarized in Table I. In the upregulated genes, biological functions including cell death and survival, and/or cell growth and proliferation were observed in all 3 groups: i) the HT control only; ii) the HT + BAG3-KD only; and iii) the commonly regulated groups. On the other hand, these
2 biological functions were observed only in the downregulated genes of the $\mathrm{HT}+\mathrm{BAG} 3-\mathrm{KD}$ only group. In addition, we identified 2 unique gene networks, and these are designated as Pro-cell death and Anti-cell death, that were obtained from the upregulated genes (Fig. 4). The Pro-cell death gene network included several transcription factors, such as activating transcription factor 2 (ATF2), CCAAT/enhancer binding protein $\beta$ (CEBPB), DNA damage inducible tran- 
A

HT control

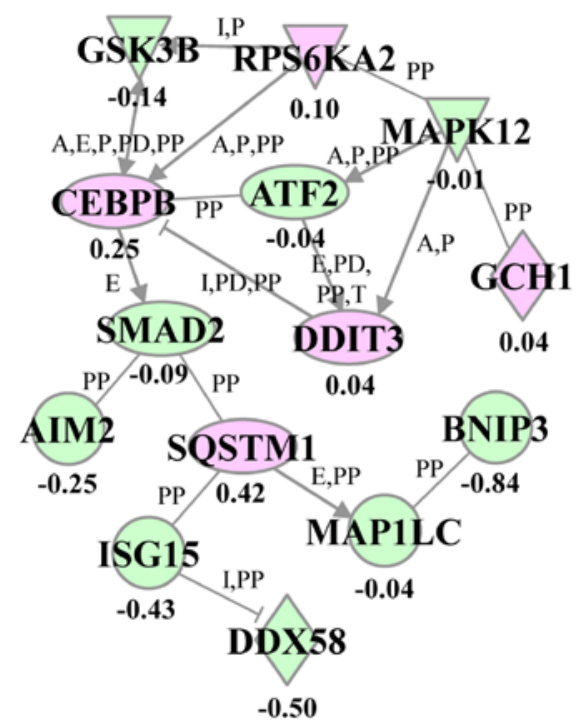

Pro-cell death

HT \& BAG3-KD

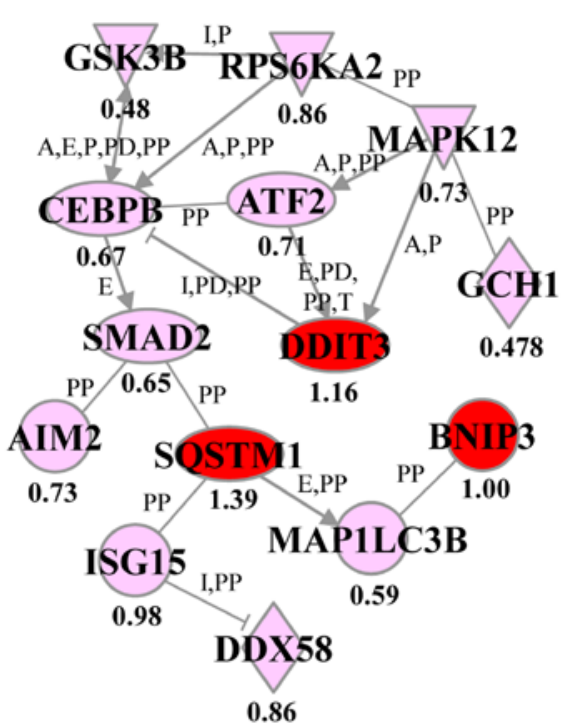

$\mathrm{B}$

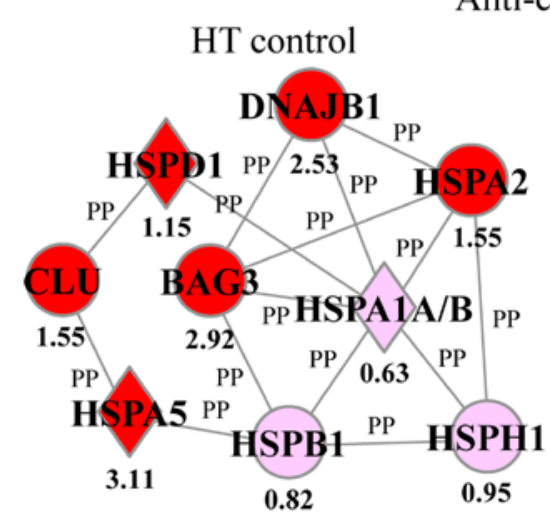

Anti-cell death

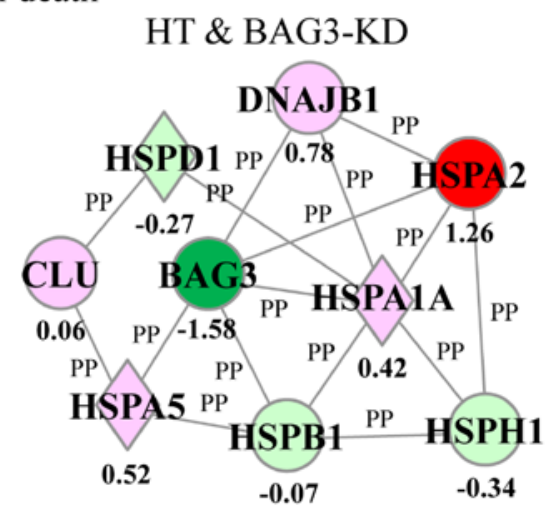

\section{Edge labels}

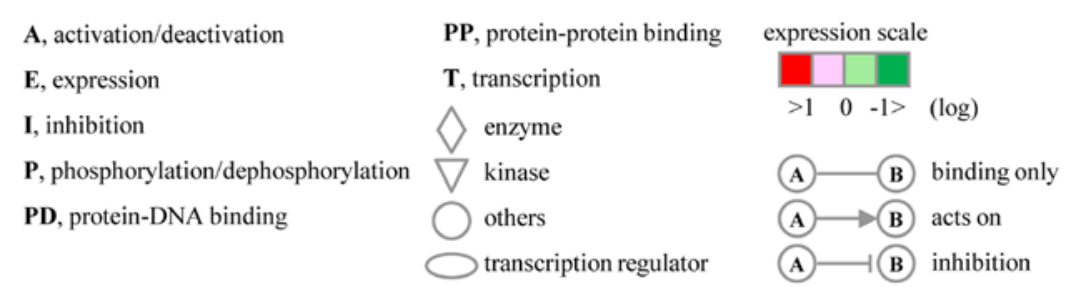

Figure 4. Gene networks, (A) Pro-cell death and (B) Anti-cell death. Upregulated genes in HSC-3 cells subjected to both hyperthermia (HT) and transfection with small interfering RNA against BAG3 (siBAG) were analyzed using the Ingenuity pathway analysis tools. Logarithmic scales of the expression levels of genes are shown. The network is represented graphically with nodes (genes) and edges (the biological associations between the nodes). HT control indicates exposure to HT and transfection with luciferase siRNA; HT + BAG3-KD indicates exposure to HT and transfection with siBAG.

script 3 (DDIT3), SMAD family member 2 (SMAD2) and sequestosome 1 (SQSTM1), as well as BCL2/adenovirus E1B $19 \mathrm{kDa}$ interacting protein 3 (BNIP3), and was associated with the biological function of the induction of cell death (Fig. 4A). The Anti-cell death gene network contained several HSPs, such as DNAJB1, HSPA1A, HSPA5, HSPB1, HSPD1, and HSPH1, as well as BAG3 and clusterin (CLU), and was associated with the biological function of the prevention of cell death (Fig. 4B). The expression levels of genes in the Pro-cell death and Anti-cell death gene networks were significantly elevated and reduced in the HT + BAG3-KD group compared to those in the HT control group, respectively (Fig. 4A and B). As expected, the mRNA expression level of BAG3 was markedly decreased in the HT + BAG3-KD group as detected by the microarray system (Fig. 4B).

\section{Discussion}

BAG3, a co-chaperone of the HSPA family of proteins, is well known as a cytoprotective protein that acts against various stresses, including heat stress $(11,12,16,21-25)$. In the present study, the almost complete silencing of BAG3 significantly 
enhanced sensitivity of human OSCC HSC-3 cells to HT. This finding is compatible with those of our previous studies $(17,18)$. In addition, using global-scale microarray and bioinformatics analyses, we herein identified genes and gene networks involved in the enhancement of HT sensitivity in BAG3-KD OSCC cells.

Our functional category analysis demonstrated that biological functions including cell death and survival, and cell growth and proliferation were observed in the upregulated genes in the cells from the HT + BAG3-KD group (Table I). Of note, we also successfully identified 2 unique gene networks, designated as Pro-cell death and Anti-cell death (Fig. 4). The Pro-cell death gene network consisted of 14 genes and was principally associated with the biological function of the induction of cell death. A marked induction of genes in this network was observed in the HT + BAG3-KD group compared to the HT control group (Fig. 4A). This network included 3 basic-region leucine zipper (bZIP) transcription factors, ATF2 (31), CEBPB (32) and DDIT3 (33), which have been reported to induce cell death. Homo- or hetero-dimeric protein complexes of the bZIP protein function as repressors and activators of transcription (34); associations have been identified between DDIT3 and both ATF2 and CEBPB (34-36). The activation of these bZIP transcription factors has also been reported to be regulated by kinases, such as glycogen synthase kinase $3 \beta$ (GSK3 $\beta$ ) (37), ribosomal protein S6 kinase, $90 \mathrm{kDa}$, polypeptide 2 (RPS6KA2) (38) and mitogen-activated protein kinase 12 (MAPK12) (39). Moreover, absent in melanoma 2 (AIM2) (40), BNIP3 (41), DEAD box polypeptide 58 (DDX58) (42), GTP cyclohydrolase 1 (GCH1) (43), ISG15 ubiquitin-like modifier (ISG15) (44), microtubule-associated protein 1 light chain 3 beta (MAP1LC3B) (45), SMAD2 (46), and SQSTM1 (47) have been reported to exert cell-damaging effects.

On the other hand, the expression levels of genes in the Anti-cell death gene network were significantly decreased in the HT + BAG3-KD group compared to those in the HT control group (Fig. 4B). This gene network consisted of 9 chaperone genes, 7 HSPs, CLU and BAG3. It is well known that HSPs protect cells both by protein chaperoning and refolding and by directly interfering with the cell death pathway $(7,8)$. HSPs such as DNAJB1 (48), HSPA1A (48,49), HSPA2 (50), HSPA5 (51), HSPB1 (52), HSPD1 (49) and HSPH1 (53) were found to be associated with the prevention of cell death. Of note, BAG3 silencing markedly decreased the expression levels of CLU, DNAJB1, HSPA5, HSPB1, HSPD1 and HSPH1 in HSC-3 cells induced by HT exposure (Fig. 4B). CLU is a secreted or cytosolic chaperone that is expressed under certain stress conditions such as heat shock (54), and secretory human CLU has been reported to decrease the rate of cell death of human breast cancer cells (55). In addition, protein-protein interactions have been reported between BAG3 and DNAJB1 (12), HSPA5 (56) and HSPB1 (12) under in vitro experimental conditions.

Taken together, our results suggest that an increase in gene expression in the Pro-cell death gene network, and the decrease in gene expression in the Anti-cell death gene network may be closely associated with the enhancement of HT-induced cell death by BAG3-KD in OSCC cells. However, the interaction between gene expression and the enhancement of the HT effects remains a subject for further study. In clinical fields, HT combined with radiotherapy and/or chemotherapy has been used as a possible treatment modality for various types of cancer (1-4).
However, the thermotolerance resulting from the elevation of HSP expression and other cytoprotective proteins in some cancer cells remains a disadvantage, diminishing the effects of HT $(5,6)$. The functional silencing of BAG3, a co-chaperone of the HSPA family of proteins, may effectively enhance the sensitivity of cancer cells to HT. Therefore, the targeting of BAG3 in combination with HT may become a promising therapeutic approach for the treatment of cancer $(17,18)$.

\section{Acknowledgements}

The present study was supported in part by a Grant-in-Aid for Challenging Exploratory Research (23650303) and a Grant-in-Aid for Scientific Research B (24310046) from Japan Society for the Promotion of Science, and by research grants from the University of Toyama.

\section{References}

1. van der Zee J, González González D, van Rhoon GC, van Dijk JD, van Putten WL and Hart AA: Comparison of radiotherapy alone with radiotherapy plus hyperthermia in locally advanced pelvic tumours: a prospective, randomised, multicentre trial. Dutch Deep Hyperthermia Group. Lancet 355: $1119-1125,2000$.

2. Harima Y, Nagata K, Harima K, Ostapenko VV, Tanaka Y and Sawada S: A randomized clinical trial of radiation therapy versus thermoradiotherapy in stage IIIB cervical carcinoma. Int J Hyperthermia 17: 97-105, 2001.

3. Westermann A, Mella O, Van Der Zee J, Jones EL, Van Der Steen-Banasik E, Koper P, Uitterhoeve AL, De Wit R, Van Der Velden J, Burger C, et al: Long-term survival data of triple modality treatment of stage IIB-III-IVA cervical cancer with the combination of radiotherapy, chemotherapy and hyperthermia - an update. Int J Hyperthermia 28: 549-553, 2012.

4. Cihoric N, Tsikkinis A, van Rhoon G, Crezee H, Aebersold DM, Bodis S, Beck M, Nadobny J, Budach V, Wust P, et al: Hyperthermia-related clinical trials on cancer treatment within the ClinicalTrials.gov registry. Int J Hyperthermia 31: 609-614, 2015.

5. Li GC, Mivechi NF and Weitzel G: Heat shock proteins, thermotolerance, and their relevance to clinical hyperthermia. Int $\mathrm{J}$ Hyperthermia 11: 459-488, 1995.

6. Nollen EA, Brunsting JF, Roelofsen H, Weber LA and Kampinga HH: In vivo chaperone activity of heat shock protein 70 and thermotolerance. Mol Cell Biol 19: 2069-2079, 1999.

7. Beere HM: 'The stress of dying': the role of heat shock proteins in the regulation of apoptosis. J Cell Sci 117: 2641-2651, 2004.

8. Lanneau D, Wettstein G, Bonniaud P and Garrido C: Heat shock proteins: cell protection through protein triage. ScientificWorldJournal 10: 1543-1552, 2010.

9. Ohtsuka K and Hata M: Molecular chaperone function of mammalian Hsp70 and Hsp40 - a review. Int J Hyperthermia 16: $231-245,2000$

10. Vos MJ, Hageman J, Carra S and Kampinga HH: Structural and functional diversities between members of the human HSPB, HSPH, HSPA, and DNAJ chaperone families. Biochemistry 47: 7001-7011, 2008

11. Kabbage M and Dickman MB: The BAG proteins: a ubiquitous family of chaperone regulators. Cell Mol Life Sci 65: 1390-1402, 2008.

12. Taipale M, Tucker G, Peng J, Krykbaeva I, Lin ZY, Larsen B, Choi H, Berger B, Gingras AC and Lindquist S: A quantitative chaperone interaction network reveals the architecture of cellular protein homeostasis pathways. Cell 158: 434-448, 2014.

13. Franceschelli S, Rosati A, Lerose R, De Nicola S, Turco MC and Pascale M: Bag3 gene expression is regulated by heat shock factor 1. J Cell Physiol 215: 575-577, 2008.

14. Du ZX, Zhang HY, Meng X, Gao YY, Zou RL, Liu BQ, Guan Y and Wang HQ: Proteasome inhibitor MG132 induces BAG3 expression through activation of heat shock factor 1. J Cell Physiol 218: 631-637, 2009. 
15. Pagliuca MG, Lerose R, Cigliano S and Leone A: Regulation by heavy metals and temperature of the human BAG-3 gene, a modulator of Hsp70 activity. FEBS Lett 541: 11-15, 2003.

16. Liao Q, Ozawa F, Friess H,Zimmermann A, Takayama S, Reed JC, Kleeff $J$ and Büchler MW: The anti-apoptotic protein BAG-3 is overexpressed in pancreatic cancer and induced by heat stress in pancreatic cancer cell lines. FEBS Lett 503: 151-157, 2001.

17. Yunoki T, Kariya A, Kondo T, Hayashi A and Tabuchi Y: The combination of silencing BAG3 and inhibition of the JNK pathway enhances hyperthermia sensitivity in human oral squamous cell carcinoma cells. Cancer Lett 335: 52-57, 2013.

18. Yunoki T, Tabuchi Y, Hayashi A and Kondo T: BAG3 protects against hyperthermic stress by modulating NF- $\kappa \mathrm{B}$ and ERK activities in human retinoblastoma cells. Graefes Arch Clin Exp Ophthalmol 253: 399-407, 2015.

19. Bonelli P, Petrella A, Rosati A, Romano MF, Lerose R, Pagliuca MG, Amelio T, Festa M, Martire G, Venuta S, et al: BAG3 protein regulates stress-induced apoptosis in normal and neoplastic leukocytes. Leukemia 18: 358-360, 2004.

20. Tabuchi Y, Ando H, Takasaki I, Feril LB Jr, Zhao QL, Ogawa R, Kudo N, Tachibana K and Kondo T: Identification of genes responsive to low intensity pulsed ultrasound in a human leukemia cell line Molt-4. Cancer Lett 246: 149-156, 2007.

21. Chiappetta G, Ammirante M, Basile A, Rosati A, Festa M, Monaco M, Vuttariello E, Pasquinelli R, Arra C, Zerilli M, et al: The antiapoptotic protein BAG3 is expressed in thyroid carcinomas and modulates apoptosis mediated by tumor necrosis factor-related apoptosis-inducing ligand. J Clin Endocrinol Metab 92: 1159-1163, 2007.

22. Festa M, Del Valle L, Khalili K, Franco R, Scognamiglio G, Graziano V, De Laurenzi V, Turco MC and Rosati A: BAG3 protein is overexpressed in human glioblastoma and is a potential target for therapy. Am J Pathol 178: 2504-2512, 2011.

23. Rosati A, Graziano V, De Laurenzi V, Pascale M and Turco MC: BAG3: a multifaceted protein that regulates major cell pathways. Cell Death Dis 2: e141, 2011.

24. Nymoen DA, Hetland Falkenthal TE, Holth A, Ow GS, Ivshina AV, Tropé CG, Kuznetsov VA, Staff AC and Davidson B: Expression and clinical role of chemoresponse-associated genes in ovarian serous carcinoma. Gynecol Oncol 139: 30-39, 2015.

25. Liu P, Xu B, Li J and Lu H: BAG3 gene silencing sensitizes leukemic cells to bortezomib-induced apoptosis. FEBS Lett 583: 401-406, 2009

26. Kariya A, Furusawa Y, Yunoki T, Kondo T and Tabuchi Y: A microRNA-27a mimic sensitizes human oral squamous cell carcinoma HSC-4 cells to hyperthermia through downregulation of Hsp110 and Hsp90. Int J Mol Med 34: 334-340, 2014.

27. Laemmli UK: Cleavage of structural proteins during the assembly of the head of bacteriophage T4. Nature 227: 680-685, 1970

28. Towbin H, Staehelin T and Gordon J: Electrophoretic transfer of proteins from polyacrylamide gels to nitrocellulose sheets: procedure and some applications. Proc Natl Acad Sci USA 76: 4350-4354, 1979.

29. Tabuchi Y, Takasaki I, Doi T, Ishii Y, Sakai H and Kondo T: Genetic networks responsive to sodium butyrate in colonic epithelial cells. FEBS Lett 580: 3035-3041, 2006.

30. Tabuchi Y, Yunoki T, Hoshi N, Suzuki N and Kondo T: Genes and gene networks involved in sodium fluoride-elicited cell death accompanying endoplasmic reticulum stress in oral epithelial cells. Into J Mol Sci 15, 8959-8978, 2014.

31. Baan B, van Dam H, van der Zon GC, Maassen JA and Ouwens DM: The role of c-Jun N-terminal kinase, p38, and extracellular signal-regulated kinase in insulin-induced Thr69 and Thr71 phosphorylation of activating transcription factor 2 . Mol Endocrinol 20: 1786-1795, 2006.

32. Pan HC, Yang CN, Hung YW, Lee WJ, Tien HR, Shen CC, Sheehan J, Chou CT and Sheu ML: Reciprocal modulation of C/EBP- $\alpha$ and $C / E B P-\beta$ by IL-13 in activated microglia prevents neuronal death. Eur J Immunol 43: 2854-2865, 2013.

33. Zinszner H, Kuroda M, Wang X, Batchvarova N, Lightfoot RT, Remotti H, Stevens JL and Ron D: CHOP is implicated in programmed cell death in response to impaired function of the endoplasmic reticulum. Genes Dev 12: 982-995, 1998.

34. Newman JR and Keating AE: Comprehensive identification of human bZIP interactions with coiled-coil arrays. Science 300: 2097-2101, 2003

35. Reinke AW, Baek J, Ashenberg O and Keating AE: Networks of bZIP protein-protein interactions diversified over a billion years of evolution. Science 340: 730-734, 2013.

36. Behrends C, Sowa ME, Gygi SP and Harper JW: Network organization of the human autophagy system. Nature 466: 68-76, 2010.
37. Tang QQ, Grønborg M, Huang H, Kim JW, Otto TC, Pandey A and Lane MD: Sequential phosphorylation of CCAAT enhancer-binding protein beta by MAPK and glycogen synthase kinase 3 beta is required for adipogenesis. Proc Natl Acad Sci USA 102: 9766-9771, 2005

38. Lee S, Shuman JD, Guszczynski T, Sakchaisri K, Sebastian T, Copeland TD, Miller M, Cohen MS, Taunton J, Smart RC, et al: RSK-mediated phosphorylation in the C/EBP $\beta$ leucine zipper regulates DNA binding, dimerization, and growth arrest activity. Mol Cell Biol 30: 2621-2635, 2010.

39. Tibbles LA and Woodgett JR: The stress-activated protein kinase pathways. Cell Mol Life Sci 55: 1230-1254, 1999.

40. Beamer WG, Shultz KL, Coombs HF III, DeMambro VE, Reinholdt LG, Ackert-Bicknell CL, Canalis E, Rosen CJ and Donahue LR: BMD regulation on mouse distal chromosome 1 , candidate genes, and response to ovariectomy or dietary fat. J Bone Miner Res 26: 88-99, 2011

41. Wang EY, Gang H, Aviv Y, Dhingra R, Margulets V and Kirshenbaum LA: p53 mediates autophagy and cell death by a mechanism contingent on Bnip3. Hypertension 62: 70-77, 2013.

42. Hiscott J, Lin R, Nakhaei P and Paz S: MasterCARD: a priceless link to innate immunity. Trends Mol Med 12: 53-56, 2006.

43. Pickert G, Lim HY, Weigert A, Häussler A, Myrczek T, Waldner M, Labocha S, Ferreirós N, Geisslinger G, Lötsch J, et al: Inhibition of GTP cyclohydrolase attenuates tumor growth by reducing angiogenesis and M2-like polarization of tumor associated macrophages. Int J Cancer 132: 591-604, 2013.

44. YángüezE, García-Culebras A,Frau A,LlompartC,Knobeloch KP, Gutierrez-Erlandsson S, García-Sastre A, Esteban M, Nieto A and Guerra S: ISG15 regulates peritoneal macrophages functionality against viral infection. PLoS Pathog 9: e1003632, 2013.

45. Yu L, Wan F, Dutta S, Welsh S, Liu Z, Freundt E, Baehrecke EH and Lenardo M: Autophagic programmed cell death by selective catalase degradation. Proc Natl Acad Sci USA 103: 4952-4957, 2006.

46. Lin Y, Zhang B, Liang H, Lu Y, Ai X, Zhang B and Chen X: JNK inhibitor SP600125 enhances TGF- $\beta$-induced apoptosis of RBE human cholangiocarcinoma cells in a Smad-dependent manner. Mol Med Rep 8: 1623-1629, 2013.

47. Huang S, Yang ZJ, Yu C and Sinicrope FA: Inhibition of mTOR kinase by AZD8055 can antagonize chemotherapy-induced cell death through autophagy induction and down-regulation of p62/sequestosome 1. J Biol Chem 286: 40002-40012, 2011.

48. Evert BO, Wüllner U and Klockgether T: Cell death in polyglutamine diseases. Cell Tissue Res 301: 189-204, 2000.

49. Veereshwarayya V, Kumar P, Rosen KM, Mestril R and Querfurth HW: Differential effects of mitochondrial heat shock protein 60 and related molecular chaperones to prevent intracellular beta-amyloid-induced inhibition of complex IV and limit apoptosis. J Biol Chem 281: 29468-29478, 2006.

50. Dix DJ, Allen JW, Collins BW, Poorman-Allen P, Mori C, Blizard DR, Brown PR, Goulding EH, Strong BD and Eddy EM: HSP70-2 is required for desynapsis of synaptonemal complexes during meiotic prophase in juvenile and adult mouse spermatocytes. Development 124: 4595-4603, 1997.

51. Zhou H, Zhang Y, Fu Y, Chan L and Lee AS: Novel mechanism of anti-apoptotic function of $78-\mathrm{kDa}$ glucose-regulated protein (GRP78): endocrine resistance factor in breast cancer, through release of B-cell lymphoma 2 (BCL-2) from BCL-2-interacting killer (BIK). J Biol Chem 286: 25687-25696, 2011.

52. Tchivilev I, Madamanchi NR, Vendrov AE, Niu XL and Runge MS: Identification of a protective role for protein phosphatase 1cgammal against oxidative stress-induced vascular smooth muscle cell apoptosis. J Biol Chem 283: 22193-22205, 2008.

53. Saito Y, Yamagishi N, Ishihara K and Hatayama T: Identification of alpha-tubulin as an hsp105alpha-binding protein by the yeast two-hybrid system. Exp Cell Res 286: 233-240, 2003.

54. Viard I, Wehrli P, Jornot L, Bullani R, Vechietti JL, Schifferli JA, Tschopp J and French LE: Clusterin gene expression mediates resistance to apoptotic cell death induced by heat shock and oxidative stress. J Invest Dermatol 112: 290-296, 1999.

55. Flanagan L, Whyte L, Chatterjee $\mathrm{N}$ and Tenniswood M: Effects of clusterin over-expression on metastatic progression and therapy in breast cancer. BMC Cancer 10: 107, 2010.

56. Kong DH, Zhang Q, Meng X, Zong ZH, Li C, Liu BQ, Guan Y and Wang HQ: BAG3 sensitizes cancer cells exposed to DNA damaging agents via direct interaction with GRP78. Biochim Biophys Acta 1833: 3245-3253, 2013. 